\title{
Conservation meets capitalism in Florida
}

An alternative financial strategy for coral-reef restoration as government funding dries up.

\section{Daniel Cressey}

23 February 2012

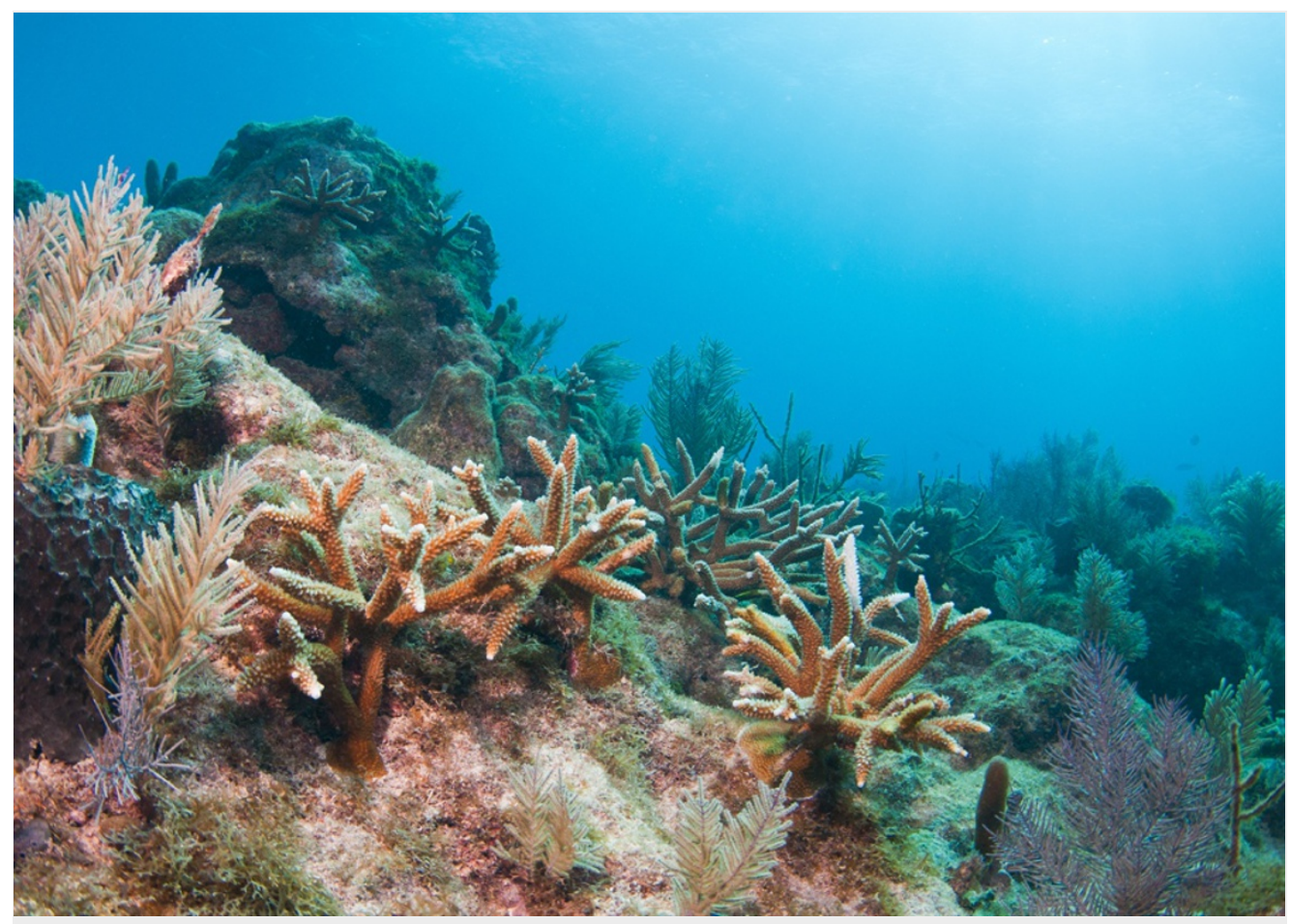

Tim Grollimund/Coral Restoration Foundation

Reef restoration is an expensive business, but conservationists are looking for ways to have it pay for itself.

Off the coast of Florida, huge coral nurseries are being cultivated to restore the region's reefs. But as a government grant for the work runs out, an alternative approach to securing funding is being explored.

Much conservation work has been predicated on the idea that habitats such as rainforests and coral reefs are of immeasurable value, but the concept of 'payment for ecosystem services' is now coming to the fore, with scientists looking to put a monetary value on ecosystems. Earlier this month, researchers and conservationists met in Florida to discuss applying this strategy to the coral reefs that surround the state's famous Keys and make up the third largest barrier reef in the world.

Since 2009, fuelled by money set aside to stimulate the US economy, researchers working off the coast of Florida have successfully established nurseries containing thousands of corals in the hope that they can be used to repair damaged and valuable reef habitats. But the stimulus money is running out, and if the nurseries are to survive they will have to become self-financing.

Enter Brett Howell of Georgia Aquarium in Atlanta. Howell has been studying the idea of payments for marine-ecosystem services and organized a meeting in Key Largo earlier this month to explore whether private money might fill the government-funding gap.

"Everybody has seen donations decline and federal budgets decline with the worldwide economic issues going on, so everybody is fairly open to somehow trying to get the people who are benefiting from the work you're doing to help contribute," says Howell. "These ideas have worked fairly well in a lot of terrestrial environments; they haven't really been tried in the marine environment."

\section{Eco-valuation}

Historically, the value assigned to ecosystems has been determined by what can be removed from those systems, be it lumber in forests or fish from seas. Recently, some environmentalists have been trying to put a value on more nebulous values, from tourism income to the economic value of mitigating climate change through carbon sequestration. 
Howell says it is too early to say exactly how such payments could be extracted in Florida, and some options — such as mandatory fees for access - are explicitly ruled out by the laws that govern the reefs.

In other parts of the world, the options under exploration include voluntary payments by reef tour operators making use of areas set aside by Mexican fishermen, and payments from resort owners for the services provided by the beaches that they rely on to bring in tourists.

The key, says Tundi Agardy, director of the marine ecosystem services programme at the non-governmental organization (NGO) Forest Trends, based in Washington DC, which is working on both these projects, is to create decentralized systems that produce a continual income, rather than one-off user fees, such as those paid by scuba divers in, for example, parts of the Red Sea.

"What compels people to explore the feasibility of these tools is a recognition that there's not enough money to do what needs to be done," says Agardy, who was at the meeting.

\section{Clear context}

The approach of soliciting payments for ecosystem services only really took off after the Millennium Ecosystem Assessment appraisal of the world's environment was completed in 2005, says Caroline Hattam, an environmental economist at the Plymouth Marine Laboratory, UK. It has been slower to take off in the marine sphere, where property rights are generally less clear-cut.

In addition, some conservationists are wary about the idea of placing a monetary value on the environment, rather than preserving it simply because that is the right thing to do. But Hattam says, "The moral imperative has been out there for a very long time and it's not made a lot of difference. The idea behind valuing the environment is to put it in a decision context, and money is often something that's understood a lot more clearly."

Although these are very early days, the feedback from the meeting was positive, says Howell, who is starting work on a business case outlining possible ways that corals could start to pay for themselves.

"A number of NGOs, their bread and butter of how they've operated is a donation-based mechanism," he says. "Getting them in the same room to get them thinking outside the box will, over time, really serve us well to get us to a longer term vision for what could happen with Florida's coral reefs."

Nature | doi:10.1038/nature.2012.10101 